\title{
Prevention and Management of Periampullary Tumors in Familial Adenomatous Polyposis
}

\author{
Naoki Hashimoto \\ School of Medicine, Kinki University, Osaka Sayama, Japan \\ Email:gojigen000@gmail.com
}

Received 1 January 2016; accepted 17 January 2016; published 22 January 2016

Copyright (C) 2016 by author and OALib.

This work is licensed under the Creative Commons Attribution International License (CC BY). http://creativecommons.org/licenses/by/4.0/

(c) (i) Open Access

\begin{abstract}
Familial adenomatosis polyposis (FAP) is one of two well described forms of hereditary colorectal cancer. The primary cause of death from this symdrome is colorectal caner which develops usually by the fifth decade of life. The overall survival of FAP was significantly improved by screening by genetic testing and endoscopy with prophylactic surgery. Almost all patients with FAP develop duodenal polyposis most of which occurs in periampullary. The second leading cause of death in FAP is duodenal adenocarcinoma. Between $5 \%$ and $10 \%$ of FAP patients die from duodenal cancer, usually periampullary in origin. Therefore, I will discuss the clinicopathological features, management and prevention of duodenal neoplasma in patients with FAP.
\end{abstract}

\section{Keywords}

Familial Adenomatous Polyposis (FAP), Duodenal Adenocarcinoma, Spigelman Classfication, Pancreas-Preserving Total Duodenectomy (PPTD)

Subject Areas: Gastroenterology \& Hepatology

\section{Introduction}

Familial adenomatosis polyposis (FAP) is an autosomal dominant inherited polyposis syndrome caused by a germline mutation in the adenomatous polyposis coli (APC) gene on chromosome 5q21 [1]. The disease is characterized by the early onset of handreds to thousands of adenomas throughout the colon. Colorectal polyposis develops by age 15 years in 50\% and age 35 years in 95\% of patients. The lifetime risk of colorectal carcinoma is virtually $100 \%$ if patients are not treated by colectomy [2].

Early prophylactic colorectal surgery has changed the prognosis of patients with FAP, and now desmoid tumors and periampullary duodenal cancers are the most common causes of death in these patients, rather than 
colorectal per se [3].

After the colorectal, the duodenum is the second most affected site of polyp development in FAP [4]. Duodenal adenoma can be found in 30\% - 70\% of FAP patients [5] and the lifetime risk of these lesions approaches $100 \%$ [6]. Duodenal/periampullary adenocarcinoma is the main cause of death in FAP after colorectal cancer. These patients have a 100 - 330 fold higher risk of duodenal cancer compared with the general population [7]. Duodenal cancer is rare in the population, with an incidence of $0.01 \%-0.04 \%$. Estimates of the cumulative risk of developing duodenal cancer in FAP range from $4 \%$ at age 70 years to $10 \%$ at age 60 years [8].

This review will discuss the clinicopathological features, management and prevention of duodenal neoplasia in patients with FAP.

\subsection{The Problem}

Patients with FAP developadenoma throughout the gastrointestinal tract. Polyps can be found throughout the duodenum, but the second and third proportion and the periampullary region are the most commonly affected sites. This pattern probably reflects exposure of duodenal mucosa to bile acids, suggesting a role for these compounds in duodenal carcinogenesis [9]. Most polyps in the duodenum are adenomas, on the contary polyps in the stomach are usually benign nonadenomatous fundic gland lesions.

The risk of duodenal cancer in FAP is increased more than 100 times that of the general population. For example, of 222 FAP patients who had a total colectomy and ileorectal anastomosis at St Mark's hospital from 1948 to 1999, duodenal cancer accounted for 11 death in their group [10].

In 1989, Spigelman et al published an endoscopic and histological classfication system for evaluation of the severity of duodenal adenomatosis [11]; the Spigelman classification has become the gold standard in duodenal adenomatosis. The classfication describes five $(0$ - IV) stages. Patients are accumulated for number, size, histology and severity of dysplasia of polyps (Table 1) [12]. Stage I is mild disease whereas stage III - IV is sever duodenal polyposis. About $70 \%$ - $80 \%$ of FAP patients have stage II or III, and $20 \%$ - 30\% have stage 1 or stage IV [11].

In colonic polyposis, specific mutations in the APC gene can allow clinicians to predict the severity of disease, for example patients with mutations in codon 1309 are likely to have dense colonic polyposis and early development of colorectal cancer [13] whereas patients with mutations at the extreme ends of the gene are likely to have a milder form of disease [14]. Mutations downstream from codon 1051 seem to be associated with severe periampullary lesions.

\subsection{Screening}

Once the diagnosis of FAP is made, patients should undergo regular upper gastrointestinal endoscopy to detect duodenal disease. In general, duodenal cancers appear to develop about 10 years after the development of colorectal cancers, so it seems reasonable not to start screening until the patients reach the age of 25.

Recommendations concering the age of initiation of upper tract surveillance are not uniform. The NCCN (National Comprehensive Cancer Net Work) recommended a baseline upper gastrointestinal endoscopicexamination at 25 - 30 years of age [15]. In general, recommedations include stage 0, I every 5 years; stage II every 3 years; stage III every 12 months with consideration for surgry; and stage IV strongly consider surgery (Table 2).

Table 1. Spigelman Classification for duodenal polyposis in familial adenomatous polyposis.

\begin{tabular}{|c|c|c|c|c|}
\hline \multicolumn{5}{|c|}{ Spigelman Classification } \\
\hline Points & 0 & 1 & 2 & 3 \\
\hline Polyp number & 0 & $1-4$ & $5-20$ & $>20$ \\
\hline Polyp size (mm) & N/A & $1-4$ & $5-10$ & $>10$ \\
\hline Histology & normal & tubular & tubulovillous & villous \\
\hline Dysplasia & none & mild & moderate & sever \\
\hline
\end{tabular}

0 points $=$ Stage $0 ; 1-4$ points $=$ Stage I; $5-6$ points $=$ Stage II; $7-8$ points $=$ Stage III $9-12$ points $=$ Stage IV. 
Table 2. Recommendations for management of duodenal polyposis in familial adenomatous polyposis in relation to Spigelman classification.

\begin{tabular}{|c|c|c|c|}
\hline \multicolumn{4}{|c|}{ Recommended protocol } \\
\hline Spigelman stage & Endoscopic frequency & Chemoprevention & Surgery \\
\hline Stage 0 & 5 years & $(-)$ & $(-)$ \\
\hline Stage I & 5 years & $(-)$ & $(-)$ \\
\hline Stage II & 3 years & $(-)$ & $(-)$ \\
\hline Stage III & 12 months & $( \pm)$ & $(-)$ \\
\hline Stage IV & 12 months & $(+)$ & $(+)$ \\
\hline
\end{tabular}

\section{Treatment}

\subsection{Medical Tratment}

Cyclooxygenase-2 (COX2) is known to be an important mediator of colorectal neoplasia progression but expression of COX2 has not been extensively studied in duodenal or upper gastrointestinal adenomas. Shirvani et al. [16] found COX2 expression in normal duodenum and esophagus and significantly higher levels in esophageal dysplastic tissues. They showed that COX2 expression in Barrett's esophagus increased in response to pulses of acid or bile salts.

Non-steroidal anti-inflammatory drugs (NSAIDs) regress colorectal adenoma in FAP patients. The value of these agents for duodenal polyposis regression is unclear.

Phillips et al. [17] investigated the effect of specific COX2 inhibitor celecoxib on duodenal polyp number and total polyp area.They found a 14\% decrease in polyp number after six months of celecoxib $800 \mathrm{mg} / \mathrm{day}(\mathrm{n}=32)$ compared with placebo $(\mathrm{n}=17)$. Winde et al. [18] compared effects of sulindac suppositories $(\mathrm{n}=28)$ wih placeno $(n=10)$ on rectal and upper gastrointestinal adenoma in patients that underwent colectomy. They found complete or partial reversion of rectal polyps but no effects on duodenal and papillary adenomas.

Drug therapy of duodenal adenomas would be appropriate treatment. But most published papers find no significant effect of NSAIDs or COX2 inhibitors on duodenal adenoma regression. Duodenal mucosa is exposed to different environment factors than that in the colon. Low $\mathrm{pH}$ and bile acids may affect control of growth and malignant potential of duodenal tumors [19].

\subsection{Endoscopic Treatment}

Endoscopic treatment options for duodenal lesions include snare excision, theramal ablation, argon plasma coagulation, and photodynamic therapy (PDT). Most reports of endoscopic therapy use snare excision. However, duodenal adenomas are often flat non-polypoid structures and, therefore, difficult to remove using conventional snare excision. Endscopic treatment is usually insufficient to guarantee a polyp-free duodenum and fraught with complications. Recurrence rates of adenomatous tissue in duodenum of FAP patients treated endoscopically range from $50 \%$ to $100 \%$ [20] [21] and the treatment is associated with a high complication rate (perforation, haemorrhage, pancreatitis) (17\%). The value of endoscopic treatment of patients with stage II and III is to delay major intervention (e.g., Whipple’s operation).

\section{Surgical Treatment}

Complete duodenectomy is the only definitive means of preventing duodenal cancer. For patients who have dysplasia,adenocarcinoma,or diffuse disease for which endoscopic therapy is impractical,surgical intervention is warranted.

Pancreaticoduodenectomy (PD) is established and well described for malignant pancreatic and duodenal disease and also has traditionally been the surgical procedure of choice for diffuse polyposis [22]. In an effort to reduce the extent of resection in focal periampullary disease,several surgeons employed local resection or ampullectomy [23]. Local duodenal polyp resection has been well described in FAP, but is also associated with a high recurrence rate and significant morbidity [24]. Pancreas-Preserving Total Duodenectomy (PPTD) consists of resection of the entire duodenum with preservation of the head of the pancreas. Chung et al. [25] described 
PPTD in 1995 for four patients with FAP and one patient with duodenal trauma. It is indicated in neoplastic or preneoplastic lesions that diffusely affect the duodenal mucosa, but with no potential for extension to the regional lymph nodes, and it should not be performed in patients with confirmed cancer. The most frequent indication of PPTD is familial adenomatous polyposis of the duodenum (Spigelman IV or III with severe dysplasia). PPTD is a challenging procedure requiring refined surgical technique and very through and detailed knowledge of the peripancreatic anatomy. PPTD has many advantages compared to conventional PD. PPTD removes the duodenal mucosa in its entirety while preserving a more normal upper gut function.Moreover, PPTD decreases the number of reconstructive anastomosis from three to two, prevents the risk of anastomosis between the jejunum and a normal nondilated common hepatic duct, prevents the risk of anastomosis of the jejunum to a small pancreatic duct in a soft normal pancreas, shortens operative time, and allows for optimal postoperative surveillance of the entire upper gastrointestinal system.

\section{Conclusion}

Duodenal polyposis and adenocarcinoma have emerged as major problems in patients with FAP. Although most patients eventually develop duodenal polyps, the polyps have lower potential for malignant change compared with colonic polyps. Duodenal adenomas seem less responsive to chemoprevention with NSAIDs than colonic counterparts. The main treatment for duodenal polyposis is frequent surveillance and targeted endoscopic treatment, adjusted by severity of duodenal lesions. But in patients with sever disease, duodenectomy may be necessary.

\section{References}

[1] Alderlieste, Y.A., Rauws, E.A., Mathus-Vliegen, E.M., et al. (2013) Prospective Enteroscopic Evaluation of Jejunal Polyposis in Patients with Familial Adenomatous Polyposis and Advanced Duodenal Polyposis. Familial Cancer, 12, 51-56. http://dx.doi.org/10.1007/s10689-012-9571-1

[2] Trimboth, J.D. and Giardiello, F.M. (2002) Genetic Testing and Counseling for Hereditary Colorectal Cancer. Alimentary Pharmacology \& Therapeutics, 16, 1843-1857. http://dx.doi.org/10.1046/j.1365-2036.2002.01357.x

[3] Basford, P.J. and Bhandari, P. (2012) Endoscopic Management of Nonampullary Duodenal Polyposis. Therapeutic Advances in Gastroenterology, 5, 127-138. http://dx.doi.org/10.1177/1756283X11429590

[4] Tonelli, F., Nordi, F., Bechi, P., et al. (1985) Extracolonic Polyps in Familial Polyposis Coli and Garder’s Syndrome. Diseases of the Colon \& Rectum, 28, 664-668. http://dx.doi.org/10.1007/BF02553447

[5] Bulow, S., Bjork, J., Christensen, U., et al. (2004) Duodenal Adenomatosis in Familial Adenomatous Polyposis. Gut, 53, 381-386. http://dx.doi.org/10.1136/gut.2003.027771

[6] Heiskanen, I., Kellokumpu, I. and Jarvinen, H. (1999) Management of Duodenal Adenomas in 98 Patients with Familial Adenomatous Polyposis. Endoscopy, 31, 412-416. http://dx.doi.org/10.1055/s-1999-41

[7] Pauli, R.M., Pauli, M.E. and Hall, J.G. (1980) Gardner Syndrome and periampullary Malignancy. American Journal of Medical Genetics, 6, 205-219. http://dx.doi.org/10.1002/ajmg.1320060305

[8] Vasen, H.F., Bulow, S., Myrhoi, T., et al. (1997) Decision Analysis in the Management of Duodenal Adenomatosis in Familial Adenomatous Polyposis. Gut, 40, 716-719. http://dx.doi.org/10.1136/gut.40.6.716

[9] Bjork, J., Akerbrant, H., Iselius, L., et al. (2001) Periampullary Adenomas and Adenocarcinomas in Familial Adenomatous Polyposis: Cumulative risks and APC Gene Mutations. Gastroenterology, 121, 1127-1135. http://dx.doi.org/10.1053/gast.2001.28707

[10] Nugent, K.P., Spigelman, A.D. and Phillips, R.K. (1993) Life Expectancy after Cololectomy and Ileorectal Anastomosis for Familial Adenomatous Polyposis. Diseases of the Colon \& Rectum, 36, 1059-1062. http://dx.doi.org/10.1007/BF02047300

[11] Spigelman, A.D., Williams, C.B., Talbot, I.C., et al. (1989) Upper Gastrointestinal Cancer in Patients with Familial Adenomatous Polyposis. The Lancet, 2, 783-785. http://dx.doi.org/10.1016/S0140-6736(89)90840-4

[12] Tonelli, F., Nardi, F., Bechi, P., et al. (1985) Extracolonic Polyps in Familial Polyposis Coli and Gardner's Syndrome. Diseases of the Colon \& Rectum, 28, 664-668. http://dx.doi.org/10.1007/BF02553447

[13] Davies, D.R., et al. (1995) Sever Gardner Syndrome in Families with Mutations Restricted to a Specific Region of the APC Gene. Am J of Hum Genet, 57, 1151-1158.

[14] Evans, D.G.R., Guy, S.P. and Thakker, N. (1993) Non Peneterance and Late Appearance of Polyps in Families with Familial Adenomatous Polyposis. Gut, 34, 1389-1393. http://dx.doi.org/10.1136/gut.34.10.1389 
[15] Morpurgo, E., Vitale, G.C., Galandiuk, S., et al. (2004) Clincal Characteiietics of Familial Adenomatous Polyposis and Management of Duodenal Adenomas. Journal of Gastrointestinal Surgery, 8, 559-564.

[16] Bertario, L., Russo, A., Sala, P., et al. (2003) Hereditary Colorectal Tumor Registry. Multiple Approach to the Exploration of Genotype-Phenotype Correlations in Familial Adenomatous Polyposis. Journal of Clinical Oncology, 21, 1698-1707.

[17] Phillips, R.K., Wallace, M.H., Lynch, P.M., et al. (2002) A Randomised, Double Blind, Placebo Controlled Study of Celecoxib, a Selective Cyclooxygenase 2 Inhibitor, on Duodenal Polyposis in Familial Adenomatous Polyposis. Gut, 50, 857-860. http://dx.doi.org/10.1136/gut.50.6.857

[18] Winde, G., Schmid, K.W., Brandt, B., et al. (1997) Clinical and Genomic Influence of Sulindac on Rectal Mucosa in Familial Adenomatous Polyposis. Diseases of the Colon \& Rectum, 40, 1156-1168. http://dx.doi.org/10.1007/BF02055161

[19] Mahmoud, N.N., Dannenberg, A.J., Bilinski, R.T., et al. (1999) Administration of Anunconjugated Bile Acid Increases Duodenal Tumors in a Murine Model of Familial Adenomatous Polyposis. Carcinogenesis, 20, 299-303. http://dx.doi.org/10.1093/carcin/20.2.299

[20] Morpurgo, E., Vitale, G.C., Galandiuk, S., et al. (2004) Clinical Characteristics of Familial Adenomatous Polyposis and Management of Duodenal Adenomas. Journal of Gastrointestinal Surgery, 8, 559-564. http://dx.doi.org/10.1016/j.gassur.2004.03.001

[21] Alarcon, F.J., Burke, C.A., Church, J.M., et al. (1999) Familial Adenomatous Polyposis: Efficacy of Endoscopic and Surgical Treatment for Advanced Duodenal Adenomas. Diseases of the Colon \& Rectum, 42, 1533-1536.

[22] Penna, C., Phillips, R.K., Tiret, F., et al. (1993) Surgical Polypectomy of Duodenal Adenomas in Familial Adenomatous Polyposis. Experience of Two European Centers. British Journal of Surgery, 80, 1027-1029. http://dx.doi.org/10.1002/bjs.1800800833

[23] Clary, B.M., Tyler, D.S., Dematos, P., et al. (2000) Local Ampullary Resection with Careful Intraoperative Frozen Section Evaluation for Presumed Benign Ampullary Neoplasma. Surgery, 127, 628-633. http://dx.doi.org/10.1067/msy.2000.106532

[24] Penna, C., Bataille, N., Balladur, P., et al. (1998) Surgical Treatment of Sever Duodenal Polyposis in Familial Adenomatous Polyposis. British Journal of Surgery, 85, 665-668. http://dx.doi.org/10.1046/j.1365-2168.1998.00684.x

[25] Chung, R.S., Church, J.M. and Van Stolk, R. (1995) Pancreas-Sparing Duodenectomy: Indications, Surgical Technique, and Results. Surgery, 117, 254-259. http://dx.doi.org/10.1016/S0039-6060(05)80198-9

\author{
Abbreviations \\ Familial adenomatous polyposis (FAP), \\ Adenomatous polyposis coli (APC), \\ National Comprehensive Cancer Net Work (NCCN), \\ Cyclooxygenase-2 (COX2), \\ Non-steroidal anti-inflammatory drugs (NSAIDs), \\ Photodynamic therapy (PDT), \\ Pancreaticoduodenectomy (PD), \\ Pancreas-Preserving Total Duodenectomy (PPTD).
}

